2017-12-04

\title{
Adapting QOF to focus on wellbeing and health
}

Close, James

http://hdl.handle.net/10026.1/11213

10.1136/bmj.j5541

BMJ

BMJ

All content in PEARL is protected by copyright law. Author manuscripts are made available in accordance with publisher policies. Please cite only the published version using the details provided on the item record or document. In the absence of an open licence (e.g. Creative Commons), permissions for further reuse of content should be sought from the publisher or author. 


\title{
Adapting QOF to focus on wellbeing and health
}

\author{
James Close research fellow ${ }^{1}$, Jose M Valderas professor of health services and policy research ${ }^{2}$, \\ Richard Byng professor in primary care research ${ }^{1}$, Nicky Britten professor in applied healthcare \\ research ${ }^{3}$, Helen Lloyd senior research fellow ${ }^{1}$
}

${ }^{1}$ Community and Primary Care Research Group, Plymouth University Peninsula Schools of Medicine and Dentistry, Plymouth Science Park, Derriford, Plymouth PL6 8BX, UK; ${ }^{2}$ University of Exeter Medical School, RSJ02, Smeall Building, St Luke's Campus, Exeter EX1 2LU, UK; ${ }^{3}$ Institute of Health Services Research, University of Exeter Medical School, St Luke's Campus, Exeter EX1 2LU, UK

We welcome Marshall and Roland's editorial on the Quality and Outcomes Framework (QOF) and propose some future directions. ${ }^{1}$

QOF (or its replacement) needs an expanded notion of quality of care that accounts for fundamental features of general practice that are not currently captured. This would focus on wellbeing and keeping people in good health rather than on managing specific diseases, based on a person centred approach that recognises the roles of patient empowerment and continuity of care. It should minimise burden on practices while allowing flexibility to tailor care to individuals, taking into account the complexity of organising, delivering, and monitoring care across multiple conditions. ${ }^{2}$

This could be achieved by:

Adapting QOF to local requirements while retaining essential indicators-"QOF lite."3

A person centred evaluation framework including experiences (PREMS) and outcomes (PROMS), ${ }^{3}$ potentially enriched with practitioner experiences, organisational change, and tools to support self management and wellbeing. ${ }^{45}$

Reporting of contact data-including frequency, mode, and duration of consultations - and personnel providing basic assurances of care delivery while allowing clinicians to adapt care.

Flexible patient management and an intelligent booking system to facilitate annual reviews and promote continuity.
Whatever shape QOF takes, the primary goal should be baseline assurances and internal intelligence for quality improvements, with freedom for practices to conduct their own audits and peer-to-peer learning. The system should use simple, easily understood metrics that provide clear warning signals and should avoid tunnel vision, gaming, and perverse incentives.

\section{Competing interests: None declared.}

Full response at: http://www.bmj.com/content/359/bmj.j4681/rr-0.

1 Marshall M, Roland M. The future of the Quality and Outcomes Framework in England. BMJ 2017;359:j4681. doi:10.1136/bmj.j4681 pmid:29042348.

2 Valderas JM. Multimorbidity, not a health condition or complexity by another name. Eur $J$ Gen Pract 2015;21:213-4. doi:10.3109/13814788.2015.1108404 pmid:26679973.

3 Greenhalgh J, Dalkin S, Gooding K, et al. Functionality and feedback: a realist synthesis of the collation, interpretation and utilisation of patient-reported outcome measures data to improve patient care. Health Services and Delivery Research 2017;5:1-280. doi:10. 3310/hsdr05020 pmid:28121094.

4 Horrell J, Lloyd H, Sugavanam T, Close J, Byng R. Creating and facilitating change for Person-Centred Coordinated Care (P3C): The development of the Organisational Change Tool (P3C-OCT) [online first]. Health Expect 2017. doi:10.1111/hex.12631 pmid:29139220.

5 Lloyd HM, Pearson M, Sheaff R, et al. Collaborative action for person-centred coordinated care (P3C): an approach to support the development of a comprehensive system-wide solution to fragmented care. Health Res Policy Syst 2017;15:98. doi:10.1186/s12961017-0263-z pmid:29166917.

6 Barker I, Steventon A, Deeny SR. Association between continuity of care in general practice and hospital admissions for ambulatory care sensitive conditions: cross sectional study of routinely collected, person level data. BMJ 2017;356:;84. doi:10.1136/bmj.j84 pmid: 28148478.

Published by the BMJ Publishing Group Limited. For permission to use (where not already granted under a licence) please go to http://group.bmj.com/group/rights-licensing/ permissions 